\title{
IMAGEN 2-2012: DOLOR ABDOMINAL Y VÓMITOS EN UNA MUJER JOVEN.
}

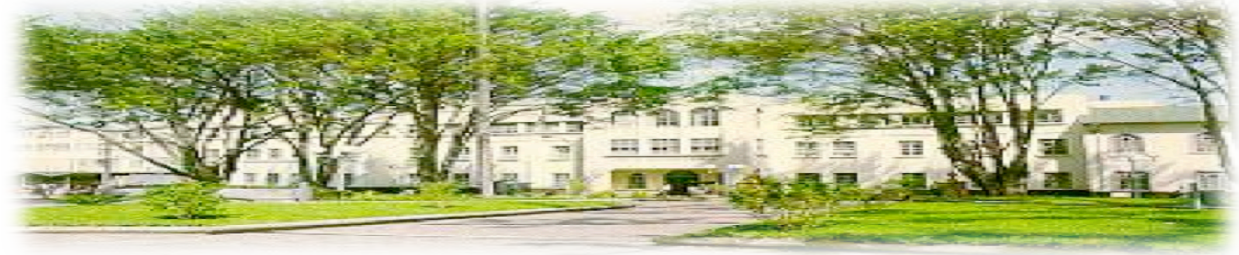

Haspital San quan de Dias. San José, Costa Riva. Fundado en 1845

Recibido:

Aceptado:
$10 / 02 / 2012$

$15 / 02 / 2012$
Sussy Vargas Solís 1 Paolo Duarte Sancho ${ }^{2}$

${ }^{1}$ Médico Residente en Radiología e Imágenes Médicas, SEP, UCR-CENDEISSS. Hospital San Juan de Dios.suvargas29@hotmail.com

${ }^{2}$ Especialista en Medicina Interna. Asistente del Servicio de Medicina Interna No. 2, Hospital San Juan de Dios. Profesor Escuela de Medicina de la U.C.R. paolo.duarte@ucr.ac.cr

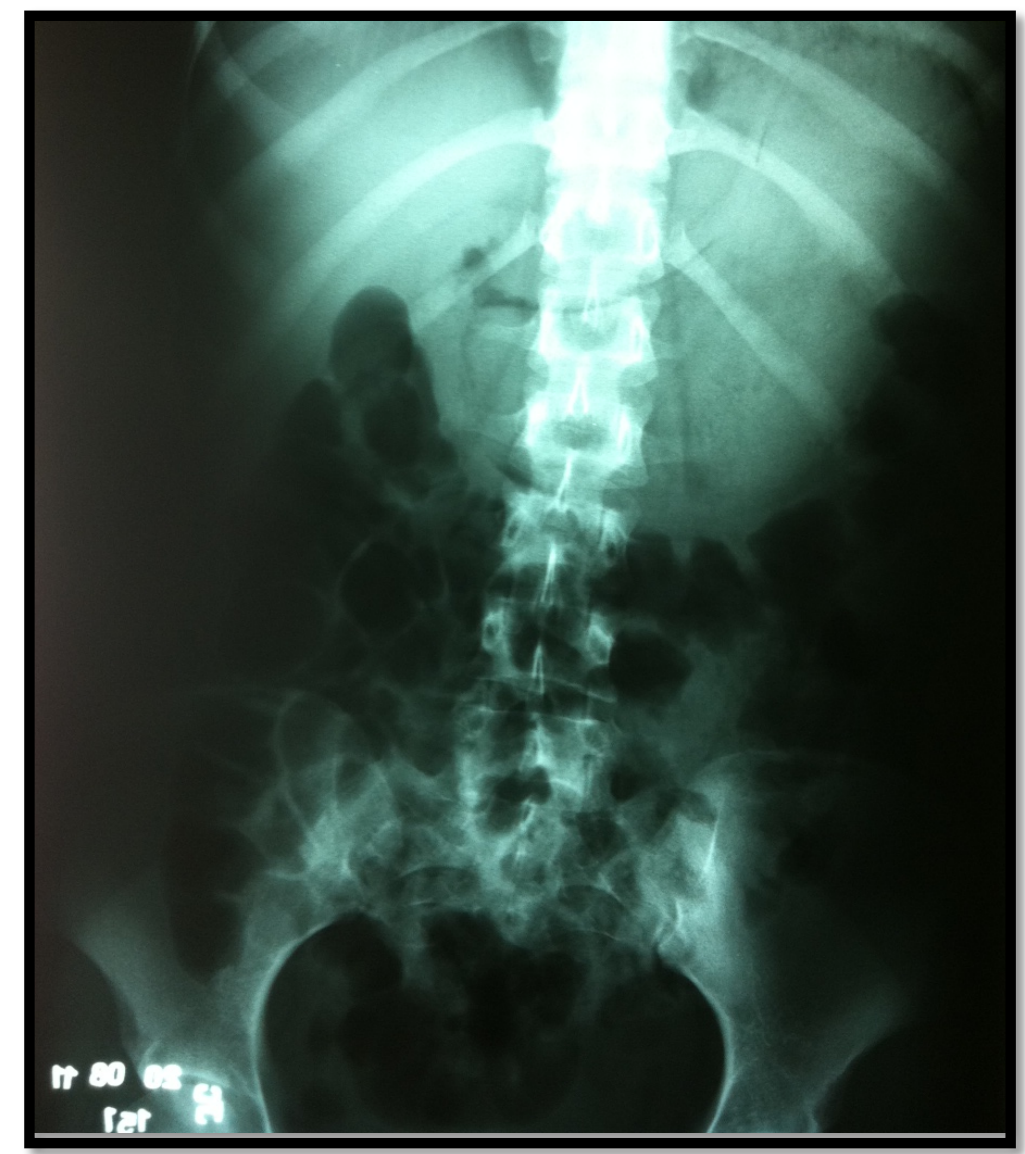




\section{CARACTERIZACIÓN DEL CASO}

Paciente femenina de 19 años, sin antecedentes médicos o quirúrgicos de relevancia, quien se presenta al Servicio de Emergencias Quirúrgicas del Hospital San Juan de Dios con cuadro agudo de dolor abdominal y vómitos. A la exploración física se palpó masa no dolorosa a nivel de epigastrio e hipocondrio izquierdo.

Se realiza una radiografía simple de abdomen en decúbito supino en la que se observa a nivel de hipocondrio izquierdo y epigastrio la presencia de la cámara gástrica con importante distensión, de paredes regulares y observándose hacia las curvaturas mayor y menor una interfase entre sólido y aire. El resto de la cámara gástrica presenta un patrón en miga de pan, el cual es característico de un bezoar. Se observa el colon transverso desplazado por la cámara gástrica. El resto de las asas presentan un patrón gaseoso normal, sin evidencia de niveles hidroaéreos. Columna vertebral de aspecto normal. No hay evidencia de calcificaciones patológicas ni otras masas. (ver portada y Fig. 1) que se presenta a continuación:

Figura 1. Radiografía simple de abdomen (acercamiento)

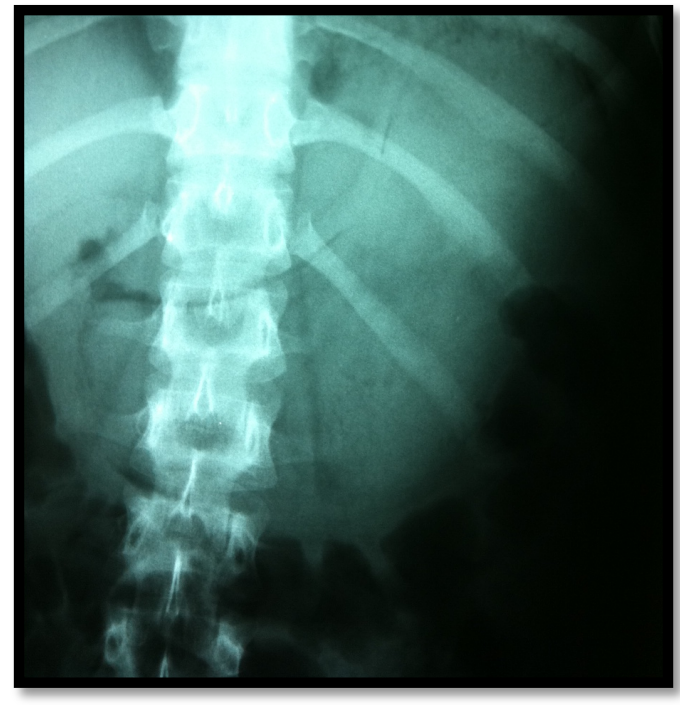

Después de ser valorada la radiografía, se somete al paciente a una endoscopía que muestra un masa compacta compuesta de cabello (Fig. 2).
Figura 2. Gastroscopía

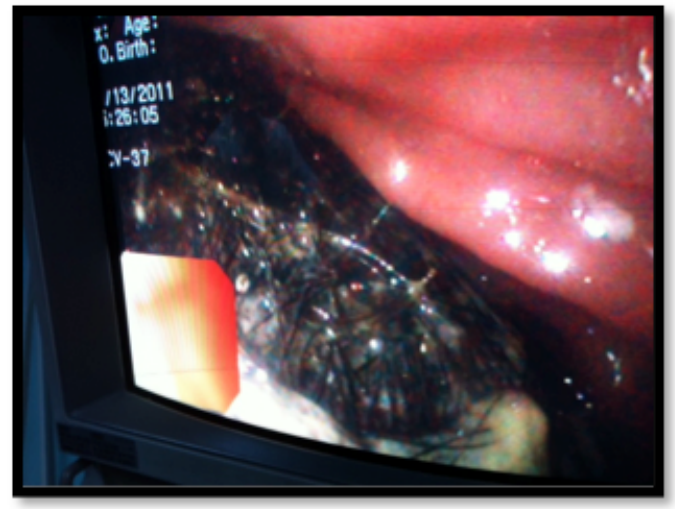

La paciente es llevada a Sala de Operaciones y se extrae un tricobezoar (Fig. 3).

Figura 3. Extracción de tricobezoar mediante laparotomía.

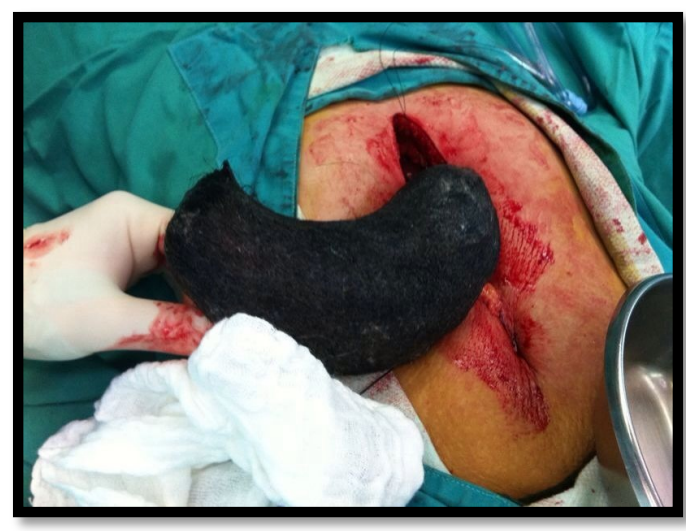

\section{DISCUSIÓN}

El término bezoar es originado de las palabras árabe "bedzehr" y persa "padzhar", los cuales significan antídoto, ya que se consideraban que protegían contra los venenos. ${ }^{(1-4)}$ Los bezoares de animales fueron utilizados con fines médicos hasta el siglo XVIII. ${ }^{(1)}$ Además también eran utilizadas como piedras preciosas. ${ }^{(2)}$ La primera referencia reportado en humanos se le atribuye a Baudamant, en 1779, durante una autopsia de un paciente que falleció por perforación gástrica $\mathrm{y}$ peritonitis. ${ }^{(1,2)}$ En 1896, Stelzner, fue el primero en efectuar el diagnóstico preoperatorio de un tricobezoar y en 1883, Schonborn realizó la primera intervención quirúrgica para extraer un tricobezoar. ${ }^{(1)}$ 
En nuestro país ya se ha reportado varios casos. ${ }^{(3-4)}$

En general, los tricobezoar ocurren más comúnmente en niños y adolescentes. Más del $90 \%$ de los casos se presentan en mujeres, sobre todo entre los 10 y 19 años. ${ }^{(1,2)}$

El tricobezoar, a diferencia de otros bezoares, no se asocian a alteraciones en la motilidad gastrointestinal, pero sí con trastornos psiquiátricos. ${ }^{(2)}$

Paralelamente, la tricotilomanía es descrita por primera vez en 1889 por Hallopeau, pero no es sino hasta 1987 que fue aceptada como trastorno psiquiátrico, con una incidencia del 0,6 al $1,6 \%{ }^{(5)}$ Ahora bien, solamente un $30 \%$ de los casos se asocia a tricofagia. ${ }^{(5)}$ Se estima que solo un $1 \%$ de los pacientes con tricofagia desarrollan tricobezoar. ${ }^{(2)}$

Únicamente en el 5\% de los casos se presentan bezoares múltiples, en la gran mayoría son únicos. ${ }^{(1)}$ Su localización más frecuente es la cámara gástrica, pero en el $15 \%$ de los pacientes, puede encontrarse una extensión al intestino delgado. ${ }^{(1)}$ El síndrome de Rapunzel consiste en un tricobezoar gástrico que se extiende, mediante una cola, al intestino delgado. ${ }^{(1-4)}$ Algunos autores mencionan como requisito que la cola se extienda al yeyuno al menos; otros, que se extienda hasta la unión ileocecal o bien, cualquier bezoar que produzca obstrucción intestinal. ${ }^{(2)}$

Sus características morfológicas se deben a varios fenómenos fisiopatológicos. El tricobezoar tiene una superficie brillante debido al moco que lo cubre. La coloración negruzca se debe a la desnaturalización proteica que ocurre por acción del contenido ácido del estómago. Su olor fétido y la halitosis que lo acompaña, se debe a la descomposición y fermentación de las grasas. ${ }^{(2)}$

$\mathrm{Su}$ presentación clínica se caracteriza por dolor abdominal, náuseas, vómitos, datos de obstrucción y peritonitis. También puede presentarse pérdida de peso, anorexia, hematemesis e intususcepción. A parte de lo anterior, pueden aparecer como complicaciones la úlcera gástrica, la pancreatitis aguda, la ictericia obstructiva y el enfisema gástrico. ${ }^{(2)}$

Con respecto al diagnóstico, las radiografías convencionales pueden ser útiles para establecer la obstrucción intestinal. Pero los bezoares pueden identificarse como tales entre un $10-18 \%$ por este medio. La tomografía axial puede ser útil, sobre todo tomando en cuenta aquellos casos en que se quiere hacer el diagnóstico diferencial con fragmentos de comida retenidos en cámara gástrica. ${ }^{(6)}$ El ultrasonido es de un valor limitado para el diagnóstico, sobre todo para los que se ubican a nivel gástrico. ${ }^{(6)}$

La mortalidad puede llegar hasta un $70 \%$, pero realmente se disminuye a un $4 \%$ con el tratamiento temprano. ${ }^{(1)}$

El manejo incluye una serie de valoraciones que van desde la extracción endoscópica o quirúrgica de la lesión, hasta el apoyo por parte de psicólogos o psiquiatras para evitar un nuevo episodio.

En este caso, se realizó la extracción del tricobezoar sin mayores contratiempos y durante el postoperatorio inmediato no se presentaron complicaciones.

\section{BIBLIOGRAFÍA}

1. Corona-Cruz JF Sánchez-Lozada R GracidaMancilla NI Palomeque-López A y VegaChavaje GR. Tricobezoar como causa de oclusión intestinal alta. Informe de un caso y revisión de la literatura. Gac Méd Mex 2005; 45: 417-419.

2. Gonuguntla V y Joshi DD. Rapunzel Syndrome: A Comprehensive Review of an Unusual Case of Trichobezoar. Clin Med Res 2009; 7: 99-102.

3. Aguilar-Arauz M Rodríguez-Gutiérrez F y Hernández-Mena C. Síndrome de Rapunzel. Reporte de un caso. Acta Méd Costarric 2003; 45: 80-83.

4. Moya A Esquivel R Torres J y Molina B. Síndrome de Rapunzel. Reporte de un caso y revisión de la literatura. Rev Med Costa Rica Centroamérica. 2008; 65: 261-265.

5. Jaramillo-Borges YM. Tricotilomanía, tricofagia y el Síndrome de Rapunzel. Acta Med Costarric 2007; 49: 4-5.

6. Ripollés T García-Aguayo J Martínez MJ y Gil P. Gastrointestinal Bezoars: Sonographic and CT Characterstrics. AJR 2001; (177): 65-69. 